\title{
Progress toward pharmacotherapies for cannabis- use disorder: an evidence-based review
}

This article was published in the following Dove Press journal:

Substance Abuse and Rehabilitation

3 May 2016

Number of times this article has been viewed

\section{Jan Copeland \\ Izabella Pokorski}

UNSW Medicine, University of New South Wales, Sydney, NSW, Australia

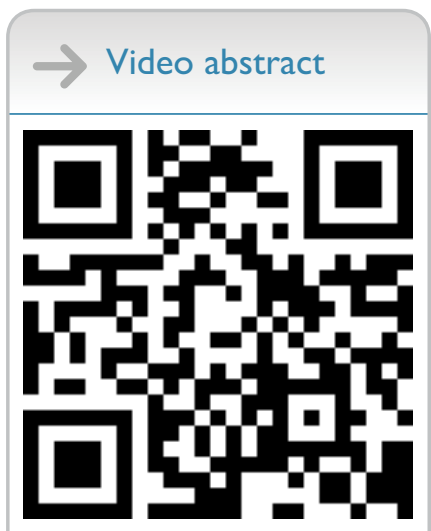

Point your SmartPhone at the code above. If you have a QR code reader the video abstract will appear. Or use: http://youtu.be/UDyjRDQsr7w
Correspondence: Jan Copeland UNSW Medicine, University of New South Wales, High Street, Kensington, Sydney, NSW 2052, Australia

Tel +6I 29385023 I

Fax +6I 293850201

Email J.Copeland@unsw.edu.au

\begin{abstract}
Cannabis is the most widely used and variably regulated drug in the world, with increasing trends of use being reported in the US, Australia, Asia, and Africa. Evidence has shown a decrease in the age of commencement of cannabis use in some developed countries and a prolongation of risk of initiation to cannabis use beyond adolescence among more recent users. Cannabis use is associated with numerous health risks and long-term morbidity, as well as risk of developing cannabis-use disorders. Cannabis users infrequently seek professional treatment, and normally do so after a decade of use. Cannabis-use disorders are currently treated using a selection of psychosocial interventions. Severity of withdrawal is a factor that increases the risk of relapse, and is the target of pharmacotherapy studies. Currently, there is no approved pharmacotherapy for cannabis-use disorders. A number of approaches have been examined, and trials are continuing to find a safe and effective medication with little abuse liability.
\end{abstract}

Keywords: marijuana, treatment, intervention, withdrawal, cannabinoid

\section{Introduction}

In the US, 23 states now have medical cannabis laws, with four of those states legalizing cannabis for recreational use. ${ }^{1}$ As debate continues about the medicinal benefits of cannabis and the potential harms of recreational use, a subset of the approximate $5 \%$ of the world's population who regularly use cannabis will develop a cannabisuse disorder, characterized by tolerance, craving, and a withdrawal syndrome. ${ }^{2}$ The 2012-2013 National Survey on Drug Use and Health reported cannabis as the most commonly used illicit drug in 2013, with 19.8 million past-month users and 8.1 million daily or almost-daily users in people over 12 years old, a dramatic increase from the 5.1 million reported in the 2005-2007 survey. ${ }^{3}$

The prevalence of cannabis-use disorders has also increased significantly, by approximately $20 \%,{ }^{1}$ with 4.2 million people reporting past-year dependence or abuse in 2013, the largest number for illicit drugs. ${ }^{3}$ This increase is speculatively explained by the increased potency of cannabis through altered tetrahydrocannabinol (THC) levels and the wider availability of cannabis. ${ }^{1,4,5}$

As the prevalence of cannabis-use disorder increases, so does demand for treatment. ${ }^{1}$ To date, psychosocial treatment remains the primary approach utilized, despite high nonresponse and relapse rates $(70 \%){ }^{6}$ There is a clear need to improve current treatment options, and medications may be a useful adjunct to aid in successful treatment outcomes; however, there are currently no approved medications for the treatment of cannabis-use disorder. ${ }^{2,6}$ 
This review aims to present information on the pharmacotherapies that have been trialed as a treatment for cannabisuse disorder. The strategies that have been explored include agonist substitution, antagonists, or modulators of noncannabinoid neurotransmitter systems assessing the effects on different aspects of cannabis use (eg, intoxication, withdrawal, self-administration). ${ }^{2}$ Research to date has been limited to human laboratory studies and small open-label or placebo-controlled clinical trials. All the studies conducted have provided useful information regarding safety and tolerability of medications combined with cannabis, as well as provided clinically relevant outcomes to guide the selection of medications to test in expensive and time-consuming clinical trials. $^{2}$

\section{Materials and methods}

This study is a review of the literature on pharmacotherapies for cannabis-use disorder. The search for articles was performed on the PubMed, Medline, and Google Scholar online databases, using the search terms "cannabis use disorder", "pharmacotherapies", "withdrawal", "intoxication", and "dependence". Additionally, an active search was conducted for related articles in the reference lists of selected publications, which included case reports, human laboratory studies, open-label studies and randomized controlled trials. An inclusion criterion was articles published in English up to January 2016. Only those studies involving human samples were included. Altogether, 56 articles were considered relevant to this review, and the results were subdivided according to their pharmacological mechanism of action.

\section{Epidemiology of cannabis use}

Global annual prevalence of cannabis use is estimated to be between $2.8 \%$ and $4.5 \% .^{7}$ As 23 states in the US have legalized medicinal cannabis, four of these states have also legalized recreational cannabis. ${ }^{1}$ In the US, lifetime prevalence of cannabis use has been reported to be between $21 \%$ and $43 \%$ and 12 -month prevalence between $4 \%$ and $10 \%$ in different large-scale epidemiological studies from 2013.,7,8 Cannabis use is typically more common among males, though sex differences appear to be diminishing. ${ }^{8,9}$

Outside the US, patterns of consumption are unevenly distributed, with the highest prevalence rates in parts of Africa, Oceania (New Zealand, Pacific Islands, and Australia), and Europe. Use appeared to stabilize or decline in $\mathrm{Canada}^{9}$ and much of Europe and New Zealand after observed peaks in the late 1990s. More recently, trends toward increased use are being reported in Asia, Africa, and Australia, and more significantly in the US. ${ }^{911-13}$
Cannabis use is most common among young adults, with recent US data citing 19\% past-month use in North Americans aged 18-25 years. ${ }^{3}$ In Australians aged 18-29 years, 21\% reported past-year use, ${ }^{11}$ and in 15 - to 34 -year-olds in the European Union, an average of $12 \%$ reported past-year use. ${ }^{12}$ Several age-related trends have recently become apparent, which include a decrease in the age of commencement of cannabis use among younger age-groups in some developed countries and a prolongation of the risk of initiation to cannabis use beyond adolescence in more recent cohorts of users. ${ }^{13-15}$ The US has reported a notable increase in adolescent cannabis use, with approximately $25 \%$ of eighth grade students and nearly $40 \%$ of high school seniors reporting use. ${ }^{16}$ This increase has been linked to a decline in perceived risk of cannabis, which may be due to the legalization of cannabis in the US and its promotion as a medicine. ${ }^{1,9}$

National data from North America and Australia also indicate increases in recent cannabis use among 50- to 59-year-olds, possibly in part reflecting an aging cohort of adolescent cannabis users from the 1970s, when cannabis use first became popular, and the promotion of medicinal cannabis. ${ }^{11,13} \mathrm{~A}$ limited number of studies examining the use patterns of indigenous communities in the US and Australia have reported significantly higher levels of cannabis use, particularly daily use, when compared to nonindigenous populations. This is an especially prominent issue among indigenous adolescents. ${ }^{17,18}$

\section{Cannabis harms}

Cannabis has very low acute toxicity, and is thus only a minor contributor to drug-related mortality; it is, however, a major public health burden in terms of morbidity. ${ }^{19,20}$ Over the decades, cannabis plants have undergone selective breeding to intensify the potency of the "high" gained from smoking, as well as to intensify the psychotropic effects experienced. ${ }^{1,4,5}$ The full extent of the consequences of high-THC cannabis strains are not yet known; however, it can be speculated that this increase is related to an increase in cannabis-use disorder and treatment sought.

There is a growing body of evidence on the accumulated risks associated with regular, long-term use, with cannabisuse disorder being the most obvious. A recent body of literature indicated that chronic cannabis use may be associated with changes in brain morphology, ${ }^{21}$ and animal studies have demonstrated that adolescent cannabis use can affect the prefrontal cortex and hippocampus, which are involved in attention, executive function, and memory, and may permanently impair adolescent neurocognitive functions. ${ }^{15}$ Although reports of neurocognitive deficits among those with 
cannabis-use disorder have been inconsistent, studies have demonstrated deficits in verbal fluency, working memory, attention regulation, visuospatial abilities, immediate and delayed memory functions, and executive functions. ${ }^{15}$ Some studies have also shown that subtle cognitive impairment affecting attention, memory, and the organization and integration of complex information, as well as loss of overall intelligence, have been found to persist even when cannabis is no longer used. ${ }^{22,23}$

Cannabis use has frequently been linked to the development of mental illness, and while cross-sectional data frequently shows an association with anxiety and depression, ${ }^{24-26}$ longitudinal studies have produced mixed evidence between the role of cannabis-related causality in the development of these disorders versus the underlying causes and comorbidity. Frequent cannabis use or use disorder has been associated with a modest risk of developing a depressive disorder, ${ }^{22}$ as found in a recent integrative analysis of four major Australasian cohorts $^{27}$ and a meta-analysis of the literature. ${ }^{28}$

Populations at greater risk of developing the adverse acute and chronic effects of cannabis use include adolescents, pregnant women, those with respiratory or cardiovascular vulnerability, and those with comorbid disorders. ${ }^{29}$ Smoking while pregnant increases the risk of delivering a child with lower birth weight. ${ }^{30-32}$ Individuals with cardiovascular disease risk exacerbating their conditions, and this risk also applies to those with respiratory disease, with such side effects as chronic cough, sputum production, wheezing, and bronchitis. ${ }^{33}$ There is also growing evidence that some of the negative respiratory effects of cannabis and tobacco may be additive. ${ }^{34}$

Onset of cannabis use during early adolescence may be a particular marker for increased risk of cannabis-use disorder, adverse physical health, compromised social development, and academic achievement. ${ }^{35,36}$ Comorbidity with other substance-use disorders and other mental health disorders is a clinical concern and is relatively common, despite ongoing debates about causality. ${ }^{37,38}$ For those vulnerable to psychotic disorders, evidence has shown that cannabis use can precipitate the disorder on average 3 years earlier, as well as increasing rates of noncompliance with medication and hospitalizations. ${ }^{39}$

\section{Cannabis-use disorder}

Although the majority of cannabis users do not report dependence, $10 \%-30 \%$ of those who ever use cannabis will go on to develop a cannabis-use disorder. ${ }^{2,40-42}$ Cannabis-use disorder is an emerging area of research, with age of onset most commonly occurring during adolescence or young adulthood, within 10 years of initiation of smoking. ${ }^{41,42}$ Rates of cannabis abuse and dependence are greater among males. ${ }^{8}$ Cannabisuse disorder has been found to commence with loss of control and continued use despite harm, with withdrawal experienced at a later age. ${ }^{43}$ There is some evidence that as prevalence of cannabis use increases, so does the incidence of cannabisuse disorder. Recent US data reports that since 2006, there has been a significant overall increase in cannabis use, with 8.1 million people aged 12 years or older using cannabis daily or almost daily in the past 12 months. ${ }^{3}$ Lifetime prevalence rates of cannabis dependence also dramatically increased to $8.3 \%$ in 2013 , a stark contrast to the $2.5 \%$ reported in $2006 .{ }^{8}$ This is indicative of the likely growing demand for the number of treatment episodes and the need for improved pharmacological and psychosocial interventions for this population.

The diagnostic criteria for cannabis-use disorders can be found in two major classification systems: the International Classification of Diseases (ICD)-10 and the Diagnostic and Statistical Manual of Mental Disorders (DSM). The most recent DSM (DSM-5) now includes a disorder specific to cannabis use, combining abuse and dependence, whereas the ICD-10 contains only a general diagnosis. The DSM-5 requires at least two criteria of tolerance, withdrawal, increasing amounts of use over time, inability to control consumption, craving, and recurrent use causing negative impacts on social, professional, and educational life, to be met within the previous 12 months. ${ }^{40}$ These signify a problematic pattern of use, leading to clinically significant impairment or distress for the user. ${ }^{44}$ Among the general adolescent population (aged 13-19 years) frequency rather than duration of use may be a better predictor of meeting criteria for cannabis-use disorder. ${ }^{45}$ Changes to the DSM diagnostic criteria include removal of the legal criterion for abuse and addition of a craving criterion, and the removal of the abuse/ dependence distinction. ${ }^{40}$

Originally, cannabis withdrawal was not included in the DSM-IV as a discrete disorder as the evidence evolved. Preclinical, clinical, and epidemiological studies over the last decade have produced irrefutable evidence of a cannabis-withdrawal syndrome. ${ }^{46,47}$ The symptoms include nightmares and strange dreams, trouble sleeping, anxiety, irritability, physical tension, low mood and depression, and reduced appetite. ${ }^{48}$ Symptoms normally occur between days 1 and 3 of abstinence and peak between days 2 and 6 , and typically last 4-14 days. ${ }^{49}$ Sleep difficulties may last for some weeks as slow-wave sleep returns to normal. Cannabis withdrawal causes functional impairment dependent on symptom severity ${ }^{48,49}$ that is predictive of relapse to cannabis use and greater levels of cannabis use following a 
quit attempt. ${ }^{50,51}$ Cannabis withdrawal may be a significant barrier in achieving abstinence, and is an important aspect in treatment planning.

\section{Cannabis treatment}

Trends in increased potency of cannabis have created an increase in use, as well as a global increase in the demand for treatment of cannabis-use disorder. ${ }^{1,3,12}$ In general, cannabis users rarely present for specialist addiction treatment. ${ }^{14}$ Adults that do present for treatment of cannabis dependence have typically used cannabis for 10 years or more and have had multiple failed quit attempts. When they do seek professional help, they not only do so due to disorder criteria, such as dependence or withdrawal symptoms, but also in response to other issues related to their cannabis use, such as relationship and family difficulties, financial problems, health concerns, and poor life satisfaction. ${ }^{14,52}$ Adolescent cannabis users presenting for treatment are less likely to believe they have a problem, and typically do so due to coercion or from family members seeking treatment for them. ${ }^{14}$

\section{Pharmacotherapies Cannabinoid medications}

As research into cannabis increases, so does knowledge surrounding the complex endocannabinoid system. The endocannabinoid system modulates neurotransmission at inhibitory and excitatory synapses in brain regions relevant to the regulation of pain, emotion, motivation, and cognition. ${ }^{52}$ This signaling system is engaged by the active component of cannabis, $\Delta^{9}$-THC, which exerts its pharmacological effects by activation of the two known cannabinoid receptors, $\mathrm{CB}_{1}$ and $\mathrm{CB}_{2}$, although there is increasing research suggesting that additional cannabinoid receptors exist. ${ }^{16,52}$ High concentrations of $\mathrm{CB}_{1}$ receptors are found in the hippocampus, neocortex, basal ganglia, and cerebellum. ${ }^{52} \mathrm{CB}_{2}$ receptors are found primarily in the peripheral tissues, and are thought to modulate immune and inflammatory responses. ${ }^{53,54}$ During chronic cannabis use, a series of neuroplastic changes occur, which continue to be poorly understood. These changes, however, are thought to lead to the development of dependence. Downregulation and desensitization of the $\mathrm{CB}_{1}$ receptors is also thought to occur, suggesting that withdrawal is driven by compensatory downregulation of the endocannabinoid system. ${ }^{54,55}$ These withdrawal symptoms promote relapse into drug use, suggesting that pharmacological strategies aimed at alleviating cannabis withdrawal might prevent relapse and reduce dependence. Cannabinoid-replacement therapy and $\mathrm{CB}_{1}$-receptor antagonism are two potential treatments for cannabis dependence that are currently under investigation. ${ }^{52,55}$

\section{Cannabinoid antagonists}

Rimonabant is a $\mathrm{CB}_{1}$-selective cannabinoid-receptor antagonist that has been found to block the effects of THC in animals. This strategy targets the addiction to the cannabis by blocking the positive subjective and reinforcing effects of the drug. ${ }^{2}$ In a randomized, double-blind, placebo-controlled study by Huestis at al, rimonabant was tested in 63 patients with a history of cannabis use. All participants were given a cannabis cigarette 2 hours after taking the medication. The medication was found to decrease feelings of intoxication and decrease heart rate. ${ }^{56}$ This study was among the first to show the utility of cannabis-receptor blocking in decreasing subjective cannabis effects. ${ }^{57}$ However, rimonabant was withdrawn from the market in 2009, due to potentially serious side effects, such as severe depression and suicidal thoughts..$^{58,59}$ Novel cannabinoid-receptor antagonists are believed to be in development.

\section{Cannabinoid agonists}

Agonist substitution involves replacing the problem drug with the same or similar drug in a safer form and route of administration. It is hypothesized that $\mathrm{CB}_{1}$-receptor agonists should reduce cannabis use by activating the same key binding sites as cannabis, reducing withdrawal and cravings. ${ }^{59}$ Agonist therapy is also thought to attenuate the acute effects of cannabis through competition at the receptor sites, facilitating abstinence. The agonist is then generally tapered off once acute withdrawal symptoms have passed. ${ }^{59}$ The cannabisagonist therapies have shown greatest promise in recent trials. Due to the experimental nature of the following studies, there are no known standard dosages testing not only drug efficacy but also balanced dosing for benefits versus side effects. ${ }^{60}$

Dronabinol is an orally bioavailable synthetic form of THC that acts as a cannabinoid-receptor agonist at the $\mathrm{CB}_{1}$ receptor. It is approved for use in the US for AIDS-related anorexia and nausea as a result of chemotherapy. ${ }^{61}$ It has shown some benefit in doses of $10-50 \mathrm{mg}$ in reducing cannabis-withdrawal symptoms, with minimal side effects in several laboratory and open-label studies. ${ }^{62,63}$ Early studies testing dronabinol on cannabis withdrawal found significant reductions in craving, anxiety, chills, depression, trouble sleeping, and decreased appetite $(10 \mathrm{mg}$, five times/day for 6 days). ${ }^{61,64,65}$ This study was successfully replicated, and found no evidence of abuse potential. ${ }^{2,62} \mathrm{~A}$ follow-up trial was conducted at $20 \mathrm{mg}$ three times a day for 8 days, which 
decreased symptoms of withdrawal but produced mild intoxication and did not decrease relapse to cannabis. ${ }^{64,65}$ There have been two case reports testing dronabinol in combination with other medications. One patient was medicated for 6 months with dronabinol (40 mg/day) and divalproex (250 mg/day), a mood stabilizer that reduces irritability and mood swings in bipolar disorder and during alcohol withdrawal. A second patient was maintained on dronabinol (10-15 mg/day) while also receiving venlafaxine ( $25 \mathrm{mg}$ /day) for depression and modafinil (100 mg as needed) to counter the energy decreases experienced with dronabinol. In both cases, patients achieved and maintained abstinence. ${ }^{64}$

In a randomized, double-blind, placebo-controlled study by Levin et al, dronabinol was provided twice daily at $40 \mathrm{mg}$ doses in a 12-week trial in 156 cannabis-dependent adults. Both groups received weekly motivational enhancement therapy and cognitive behavioral therapy. Dronabinol appeared to lower withdrawal symptoms and promote treatment retention ( $77 \%$ versus $61 \%$, respectively), but did not affect abstinence at weeks 7 and 8 (17.7\% and 15.6\% for dronabinol and placebo, respectively). Four serious adverse events were reported, but none were deemed to be study-related. ${ }^{65}$ Although there is evidence that dronabinol decreases withdrawal, it does not appear to alter levels of cannabis use significantly.

Nabilone is another cannabinoid agonist with superior bioavailability to dronabinol, with a more predictable doseresponse relationship and less individual variability in drug response. ${ }^{66}$ Promisingly, nabilone has been found to improve both cannabis-withdrawal symptoms and prevent relapse in a nonclinical, experimental laboratory-based study ${ }^{66}$ Nabilone was tested in three 8-day inpatient phases, assessing different nabilone doses $(0,6$, and $8 \mathrm{mg} /$ day $)$. Both doses were shown to reverse withdrawal-induced irritability, sleep disturbance, and appetite reduction. ${ }^{67}$ Both nabilone doses decreased laboratory measures of cannabis relapse, and patients chose to smoke fewer doses of cannabis while on nabilone compared to placebo. These positive results support further testing of nabilone in clinical populations.

The most innovative and promising pharmacotherapy currently being explored is nabiximols (Sativex), which has a 1:1 ratio of $\Delta^{9}$-THC to cannabidiol (CBD) in an oromucosal, botanically derived, cannabinoid-based spray. Nabiximols is available in 15 countries for symptomatic relief of spasticity in multiple sclerosis, and is being assessed for cancer-related pain. This drug has recently been trialed in Australia for the treatment of withdrawal symptoms. This relatively small $(n=51)$ inpatient randomized controlled trial found that nabiximols were efficacious in the reduction of both the severity and time course of cannabis withdrawal, and in retaining participants in withdrawal treatment. ${ }^{57}$

The THC component of nabiximols provides the agonist substitution, and the CBD content of nabiximols is potentially a major innovation over other $\mathrm{CB}_{1}$-receptor agonists, such as dronabinol and nabilone. $\mathrm{CBD}$ has psychoactive but not intoxicating effects. ${ }^{68}$ There is speculation about its method of action. CBD affects numerous other drug targets, including transient receptor-potential family channels, 5- $\mathrm{HT}_{1 \mathrm{~A}}$, and PPAR $\gamma$ receptors.$^{69} \mathrm{CBD}$ is present in varying degrees across different cannabis strains, although it appears largely bred out of modern illicit strains. CBD has notable anxiolytic, antidepressant, and antipsychotic properties, and can attenuate paranoia and other adverse psychological effects of THC in humans. ${ }^{68-74}$

$\mathrm{CBD}$ appears to operate at both $\mathrm{CB}_{1}$ and $\mathrm{CB}_{2}$ receptors, indirectly stimulating endogenous cannabinoid signaling by suppressing fatty acid amide hydrolase (FAAH), the enzyme that breaks down anandamide. ${ }^{69}$ Anandamide is the endogenous cannabinoid produced by the human body. This enables more anandamide to remain at the receptors, reducing the sudden withdrawal produced by abrupt cessation of cannabis use. It has also been shown to be an inverse agonist of $\mathrm{CB}_{2}$ receptors. ${ }^{70,71}$ It has been tested extensively on animals and humans, and is just entering the clinical trial phase for cannabis use. It has shown some promise in a single case study, where it was effective in reducing withdrawal symptoms and sustaining the withdrawal attempt of a cannabis-dependent patient with multiple failed quit attempts. Following maintenance on CBD (300-600 mg/day) for 11 days, the patient demonstrated no self-reported abstinence symptoms. ${ }^{73}$

It has also shown some promise as a treatment for cannabis dependence, due to its potential impact on the salience of drug cues. ${ }^{74}$ All these potential treatments need and are undergoing much further testing and replication, in order to enter the first line of treatment recommendations.

\section{Other medications}

There have been various noncannabinoid medications already used to treat other substance-use disorders, which have been evaluated in controlled inpatient studies for the treatment of cannabis withdrawal, largely with negative results.

\section{Opioid agonists and antagonists}

Clonidine, an adrenergic receptor agonist, reduced cannabiswithdrawal symptoms in rodents, presumably by reversing enhanced noradrenergic signaling during withdrawal. This 
led to testing lofexidine, an $\alpha_{2}$-adrenergic receptor agonist that is currently used to treat opioid withdrawal, in clinical studies, which was found not to diminish mood symptoms associated with withdrawal significantly, but did improve sleep and decrease cannabis relapse. Combining lofexidine and dronabinol produced the most significant improvements in sleep, withdrawal, craving, and relapse compared to placebo. ${ }^{75-77}$

Naltrexone is an opioid $\mu$-antagonist approved for treatment of alcohol and opioid dependence. In a study examining the interaction of naltrexone with smoked cannabis ( 0 or $3.27 \%$ THC) in a randomized, double-blind trial, it was found that naltrexone alone with no THC increased ratings of "liking", "take again", and "stimulated". Conversely, the naltrexone with $3.27 \%$ THC increased ratings of "liking", "take again", "stimulated", "high", "good", and "strength". It was concluded that naltrexone may increase the abuse liability of cannabinoids. ${ }^{78}$

\section{Antidepressants}

Nefazodone and mirtazapine are both antidepressants with sedative properties that enhance noradrenergic and serotonergic activity. ${ }^{79,80}$ Nefazodone is a serotonin- and norepinephrine-reuptake inhibitor and a $5-\mathrm{HT}_{2 \mathrm{~A}}$-receptor antagonist approved for the treatment of depression. ${ }^{57,78}$ During cannabis withdrawal, nefazodone at $450 \mathrm{mg}$ /day for 26 days decreased such symptoms as anxiety and muscle pain, but did not alleviate irritability, misery, or troubled sleep. ${ }^{78,79}$ Conversely, mirtazapine (30 mg/day for 14 days) reversed sleep disruption and appetite loss during cannabis withdrawal, but did not improve participants' mood or decrease relapse. ${ }^{79}$ Consistent with the laboratory data, clinical trials with bupropion and nefazodone were also negative. Bupropion is an indirect noradrenergic and dopaminergic agent used for tobacco cessation and treatment of depression, which was given at 150-300 mg/day for 28 days against placebo, and was found to worsen irritability, restlessness, depression, and troubled sleep during cannabis withdrawal. ${ }^{57,80}$ It is hypothesized that the stimulant properties of bupropion may have exacerbated abstinence-associated agitation and insomnia.

In a randomized study by Carpenter et al of cannabisdependent participants, bupropion (300 mg/day divided into two oral doses) and nefazodone (600 mg/day divided into two oral doses) were compared to placebo in a 13 -week trial. The study included a 1 week placebo lead-in and 2-week placebo washout period. All patients were given weekly sessions with a psychosocial intervention. There was no difference in cannabis use or withdrawal symptoms among those receiving bupropion, nefazodone, or placebo, and only half the patients completed the 10 -week medication phase. ${ }^{81}$

Mood disorders, especially depression, are a common comorbidity associated with cannabis use. The use of antidepressant medication in this population was explored to promote abstinence. ${ }^{82}$ Venlafaxine and fluoxetine were tested in a randomized double-blind placebo-controlled trial with depressed cannabis-dependent adolescents. ${ }^{83}$ Venlafaxine is a serotonin- and norepinephrine-reuptake inhibitor approved for the treatment of major depressive disorder, generalized anxiety disorder, social anxiety disorder, and panic disorder. In the 12-week study, no advantage was discovered for fluoxetine (10-20 mg/day for 12 weeks) over placebo on either depression or cannabis-use outcomes. A subsequent trial in 103 adult patients found that extended-release venlafaxine (375 $\mathrm{mg}$ /day for 12 weeks) was not effective relative to placebo in reducing depression, and found less abstinence in the treatment group ( $11.8 \%$ and $36.5 \%$, respectively). ${ }^{83}$ Overall, neither laboratory nor clinical studies have provided compelling evidence for the utility of antidepressants to treat cannabis-use disorders.

\section{Anxiolytics and mood stabilizers}

Given that anxiety can be a symptom of cannabis withdrawal, it was hypothesized that anxiety symptoms may be a useful treatment target. Exploratory analyses suggested that decreased anxiety predicted cannabis abstinence. The nonbenzodiazepine anxiolytic buspirone was tested in a randomized, controlled clinical trial for cannabis-use disorders. ${ }^{84}$ Cannabis-dependent patients were randomized to buspirone (60 mg/day) or placebo for 12 weeks in conjunction with a psychological intervention (two or three sessions of motivational interviewing during the first 4 weeks). The study reported a high dropout rate $(50 \%)$ and no direct effect of buspirone on self-reported anxiety, withdrawal symptoms, or craving. However, exploratory analyses suggested that decreased anxiety over the study predicted cannabis abstinence. ${ }^{84}$

Divalproex has been investigated for its mood-stabilizing properties with effects upon $\gamma$-aminobutyric acid (GABA) transmission. Divalproex is an anticonvulsant approved for the treatment of seizures and bipolar disorder, as well as migraine prophylaxis. Administered at $1,500 \mathrm{mg} /$ day for 29 days, the medication was found to decrease cannabis cravings, but increased anxiety, irritability, and fatigue and decreased cognitive performance compared to placebo. ${ }^{85}$ In an additional randomized, placebo-controlled pilot study in 25 cannabis-dependent adults, divalproex was 
adjusted to individual patient response (ranging from 250 to $2,000 \mathrm{mg} /$ day) in conjunction with cognitive behavioral therapy for a period of 8 weeks. Patients who completed the 8 weeks reported decreased irritability, cannabis craving, and cannabis use. However, there was an increased incidence of adverse reactions related to the medication, such as fatigue, headaches, drowsiness, and nausea. The adverse events related to the medication, as well as poor patient compliance, do not support the clinical utility of divalproex. ${ }^{86}$

Another mood stabilizer tested for the treatment of cannabis withdrawal is lithium carbonate. Two small preliminary open-label, inpatient laboratory studies (600-900 mg/day for 6 days and $1,000 \mathrm{mg} /$ day for 7 days) reported moderate reductions in withdrawal symptoms, ${ }^{87,88}$ but a recent randomized control study of lithium carbonate found a reduction in some specific withdrawal symptoms, such as stomachaches and nightmares, but no significant difference in overall Cannabis Withdrawal Scale scores or levels of cannabis use compared to placebo. ${ }^{89}$ There are also potential concerns regarding the safety of outpatient administration of lithium, due to its toxicity at high doses. ${ }^{88,89}$

\section{Other medications}

The hormone oxytocin has been tested in several preclinical studies, and has been shown to reduce drug reinforcement and anxiety-like behavior. A recent trial examining the effects of intranasal oxytocin found that acute administration alleviated craving and anxiety in eight cannabis users. ${ }^{90}$ These data are supported by findings that oxytocin mediates lithium's effects on cannabis withdrawal, and warrant further investigation into the utility of oxytocin for cannabis-use disorder.

Quetiapine, an atypical antipsychotic, which is a $5-\mathrm{HT}_{2 \mathrm{~A}}$ and $\mathrm{D}_{2}$ antagonist, a partial agonist at the $5-\mathrm{HT}_{1 \mathrm{~A}}$ receptor, inhibits the norepinephrine transporter. Quetiapine was given to cannabis users with schizophrenia or bipolar disorder, and was reported to reduce cannabis use over the course of treatment. ${ }^{91}$ An inpatient laboratory study comparing quetiapine at $200 \mathrm{mg}$ /day for 15 days to placebo found improved sleep quality and decreased anorexia during cannabis withdrawal. There was, however, increased craving for cannabis, and self-administration of cannabis, indicating that this drug is not an appropriate potential treatment for cannabis-use disorders. ${ }^{92}$

A small open-label study investigated the clinical utility of atomoxetine, a norepinephrine-reuptake inhibitor used for attention deficit/hyperactivity disorder (ADHD; 20-80 mg daily for 11 weeks). A reduction in cannabis use was demonstrated in cannabis-dependent individuals; however, the medication produced a number of adverse effects in the majority of patients (nausea, vomiting, dyspepsia, diarrhea).$^{93}$ A follow up placebo-controlled study evaluated the effects of atomoxetine on symptoms of ADHD and cannabis use in cannabis-dependent adults in conjunction with motivational enhancement therapy. ${ }^{94}$ Participants randomized to atomoxetine showed greater improvements in clinically assessed ADHD symptoms, but no significant effects on self-reported ADHD symptoms or cannabis use.

Entacapone, an inhibitor of catecholaminergic catabolism approved for the treatment of Parkinson's disease, was tested in a small open-label pilot study over 12 weeks on patients meeting criteria for cannabis-use disorder. As an acute maintenance treatment, entacapone at $2,000 \mathrm{mg}$ /day significantly decreased craving for cannabis in over half the patients. The drug was well tolerated, and there were no reported serious adverse events, which warrants further studies to confirm these findings. ${ }^{95,96}$

Alternative pharmacotherapy approaches continue to be explored as understanding of the neuropharmacology of cannabis-use disorders improves. ${ }^{82}$ These alternative medications have been found to treat other drugs of dependence or target similar pathways to cannabis. Animal studies showed that $\mathrm{N}$-acetylcysteine (NAC), an antioxidant, reversed alterations to the glutamine system associated with repeated self-administration of a range of addictive drugs. In an open-label study, adolescents received 2,400 $\mathrm{mg}$ of NAC daily over a 4-week period with no other intervention. The medication decreased self-reported cannabis use, as well as cannabis craving. It was generally well tolerated, but did produce some mild-to-moderate side effects. ${ }^{97}$ A follow-up 8-week double-blind, randomized, placebocontrolled trial with 116 treatment-seeking cannabisdependent adolescents (ages 15-21 years) received NAC $(1,200 \mathrm{mg})$ or placebo twice daily as well as contingency management and brief cessation counseling weekly. ${ }^{98}$ Participants receiving NAC were twice as likely to produce a negative urine-toxicology test at the end of the study compared with those receiving placebo. This difference, however, was not significant at 1-month follow-up.

In a case series assessing the effects of baclofen, a GABAreceptor agonist and antispasmodic medication, $40 \mathrm{mg} /$ day in six patients with cannabis and nicotine dependence, common side effects included sedation and lethargy. ${ }^{99}$ Despite this, the medication was well tolerated, and it was reported that withdrawal symptoms decreased in patients who maintained abstinence for between 1 and 13 months. ${ }^{99}$ In a laboratory study, baclofen did not reduce cannabis relapse, had nega- 
Table I Pharmacological trials for cannabis-use disorder

\begin{tabular}{|c|c|c|c|c|c|}
\hline Drug & $\begin{array}{l}\text { Sample } \\
\text { size (n) }\end{array}$ & Dose & Design & Results & Authors \\
\hline
\end{tabular}

\begin{tabular}{lcl}
\hline $\begin{array}{l}\text { Cannabinoid agonists } \\
\text { Oral THC }\end{array}$ & II & $10 \mathrm{mg}$ \\
Oral THC & 8 & $30,90 \mathrm{mg}$ \\
& & \\
Nabilone & II & $6,8 \mathrm{mg}$ \\
Dronabinol & 2 & $10-50 \mathrm{mg}$ \\
Cannabidiol & I & $300-600 \mathrm{mg}$ \\
Nabiximols & $5 \mathrm{I}$ & $166.4 \mathrm{mg}$
\end{tabular}

\section{Cannabinoid antagonists}

Rimonabant 63

Rimonabant

42

42

I, 3, 10, 30, $90 \mathrm{mg}$ Randomized double-blind placebocontrolled crossover

Double-blind parallel-group

Other agents

\section{Opioid antagonists}

Naltrexone I

Naltrexone

$9,23^{\mathrm{d}}$

$50 \mathrm{mg}$

Naltrexone

21

Naltrexone

29

Naltrexone

\section{2, 25, 50,}

$100 \mathrm{mg}$

Antidepressants

\begin{tabular}{|c|c|c|}
\hline Bupropion & 10 & $300 \mathrm{mg}$ \\
\hline Nefazodone & 7 & $450 \mathrm{mg}$ \\
\hline Fluoxetine & 22 & $20-40 \mathrm{mg}$ \\
\hline Lofexidine + THC & 8 & $2.4,60 \mathrm{mg}$ \\
\hline Nefazodone $e^{a, b}$ & 106 & $300 \mathrm{mg}$ \\
\hline Bupropion ${ }^{\mathrm{a}, \mathrm{b}}$ & & $150 \mathrm{mg}$ \\
\hline Entacapone & 36 & $200 \mathrm{mg}$ \\
\hline $\begin{array}{l}\text { Baclofen }{ }^{b, c} \text { or } \\
\text { mirtazapine }^{b, c}\end{array}$ & 11 & $\begin{array}{l}30,60,90 \mathrm{~m} \\
30 \mathrm{mg}\end{array}$ \\
\hline Fluoxetine & 70 & $20 \mathrm{mg}$ \\
\hline \multicolumn{3}{|l|}{ Glutamates } \\
\hline $\mathrm{N}$-acetylcysteine & 24 & $\mathrm{I}, 200 \mathrm{mg}$ \\
\hline $\mathrm{N}$-acetylcysteine & 116 & $\mathrm{I}, 200 \mathrm{mg}$ \\
\hline
\end{tabular}

\section{Anxiolytics}

\begin{tabular}{|c|c|c|c|}
\hline Buspirone & 10 & Up to $60 \mathrm{mg}$ & Open-label \\
\hline Buspirone & 50 & Up to $60 \mathrm{mg}$ & Double-blind, placebo-controlled \\
\hline \multicolumn{4}{|c|}{ Mood stabilizers } \\
\hline Lithium & 9 & $600-900 \mathrm{mg}$ & Open-label \\
\hline
\end{tabular}
crossover

Double-blind placebo-controlled crossover

Double-blind placebo-controlled crossover

Double-blind placebo-controlled crossover

Double-blind placebo-controlled crossover

Randomized double-blind placebocontrolled crossover

Randomized double-blind placebocontrolled crossover

Randomized double-blind placebocontrolled crossover

Placebo-controlled

Randomized double-blind placebocontrolled crossover

Open-label

Randomized double-blind placebocontrolled crossover

Randomized double-blind placebocontrolled crossover

Open-label

Randomized double-blind placebocontrolled
Reduced withdrawal

Reduced withdrawal

Reduced withdrawal and use Mixed results

Reduced withdrawal and use

Reduced withdrawal

Attenuated effects of cannabis, potentially serious side effects Attenuated cardiovascular effects of cannabis, removed from the market

Failed to attenuate dronabinol not urine cannabinoid levels Increased negative urine cannabinoid tests during treatment

Reduced craving and irritability Reduced cannabis use

Reduced withdrawal
McRae et $\mathrm{al}^{90}$ McRae et al ${ }^{89}$

\author{
Haney et $\mathrm{al}^{61}$ \\ Budney et $\mathrm{al}^{63}$ \\ Haney et $\mathrm{al}^{66}$ \\ Levin and Kleber ${ }^{60}$ \\ Crippa et $\mathrm{al}^{72}$ \\ Allsop et $\mathrm{al}^{57}$
}

Huestis et $\mathrm{al}^{56}$

Huestis et $\mathrm{a}^{58}$

Wachtel and de $\mathrm{Wit}^{78}$

Haney et $\mathrm{al}^{76}$

Haney et $\mathrm{al}^{79}$

Cooper and

Haney ${ }^{80}$

Greenwald and

Stitzer ${ }^{81}$

Haney et $\mathrm{al}^{83}$

Haney et $\mathrm{al}^{77}$

Cornelius et $\mathrm{al}^{87}$

Haney et $\mathrm{al}^{75}$

Carpenter et $\mathrm{al}^{84}$

Shafa and

Abdolmaleky '12

Haney et $\mathrm{al}^{82}$

Cornelius et $\mathrm{al}^{88}$

Gray et al $^{101}$

Gray et al ${ }^{102}$

Bowen et $\mathrm{al}^{92}$ 
Table I (Continued)

\begin{tabular}{|c|c|c|c|c|c|}
\hline Drug & $\mathbf{n}$ & Dose & Design & Results & Study \\
\hline Lithium & 12 & $500 \mathrm{mg}$ & Open-label & $\begin{array}{l}\text { Tolerated, reduction in } \\
\text { cannabis use }\end{array}$ & Winstock et $\mathrm{al}^{93}$ \\
\hline Lithium & 38 & $500 \mathrm{mg}$ & $\begin{array}{l}\text { Randomized double-blind placebo- } \\
\text { controlled crossover }\end{array}$ & No effect & Johnston et al ${ }^{94}$ \\
\hline Divalproex & 7 & $\mathrm{I}, 500 \mathrm{mg}$ & $\begin{array}{l}\text { Randomized double-blind placebo- } \\
\text { controlled crossover }\end{array}$ & Worsened withdrawal & Haney et $\mathrm{a}^{61}$ \\
\hline Divalproex & 25 & $\mathrm{I}, 500-2,000 \mathrm{mg}$ & $\begin{array}{l}\text { Randomized double-blind placebo- } \\
\text { controlled crossover }\end{array}$ & No effect & Levin et $\mathrm{a}^{91}$ \\
\hline \multicolumn{6}{|l|}{ Other } \\
\hline Gabapentin & 50 & $\mathrm{I}, 200 \mathrm{mg}$ & $\begin{array}{l}\text { Randomized double-blind placebo- } \\
\text { controlled crossover }\end{array}$ & $\begin{array}{l}\text { Decreased withdrawal, high } \\
\text { dropout rate }\end{array}$ & Mason et al ${ }^{103}$ \\
\hline Oxytocin & 16 & $40 \mathrm{IU}$ & $\begin{array}{l}\text { Randomized double-blind placebo- } \\
\text { controlled crossover }\end{array}$ & Decreased craving and anxiety & McRae-Clark et al ${ }^{95}$ \\
\hline Quetiapine & 14 & $200 \mathrm{mg}$ & $\begin{array}{l}\text { Within-subject double-blind } \\
\text { placebo-controlled }\end{array}$ & $\begin{array}{l}\text { Decreased withdrawal, } \\
\text { increased cannabis use }\end{array}$ & Cooper et $\mathrm{al}^{97}$ \\
\hline Varenicline & 5 & $0.5-1 \mathrm{mg}$ & Case series & $\begin{array}{l}\text { Reduced use, zero completion } \\
\text { of study due to side effects }\end{array}$ & Newcombe et al ${ }^{109}$ \\
\hline
\end{tabular}

Notes: aNefazodone dosage $300 \mathrm{mg}$; buproprion dosage $150 \mathrm{mg}$. ${ }^{\mathrm{S} S a m p l e}$ size data not available for each individual drug. ${ }^{\mathrm{C} B a c l o f e n}$ dosage $30,60,90 \mathrm{mg}$; mirtazapine dosage $30 \mathrm{mg}$. ${ }^{\mathrm{T}}$ This study had two separate sample sizes.

Abbreviation: THC, tetrahydrocannabinol.

tive effects on mood and behavior, and reduced cognitive performance across conditions. ${ }^{79}$ These results fail to support the use of baclofen for cannabis withdrawal.

Gabapentin is an alkylated analog of GABA approved in the US for the treatment of seizures and postherpetic neuralgia. It is believed to modulate GABAergic mechanisms by blocking the $\alpha_{2} \delta$ subunit of the voltage-gated calcium channel. In a 12-week, randomized, double-blind, placebocontrolled trial in 50 adults with cannabis dependence, $1,200 \mathrm{mg}$ of gabapentin was divided into three daily doses. Although there was a high dropout rate, the authors found statistically significant reduction in grams used and days of use, along with reductions in cannabis-withdrawal symptoms, marijuana cravings, sleep problems, and depression scores. Improvements in measures of executive functioning were also seen, and there were no serious adverse events. ${ }^{100,101}$ The fixed dose of $1,200 \mathrm{mg} /$ day was found to be safe and well tolerated, ${ }^{100}$ with no safety or dependence risks obtained in earlier human laboratory studies; ${ }^{102}$ however, there have been reports regarding the misuse potential of gabapentin, which may be an important consideration in future studies. ${ }^{103-105}$ Nevertheless, these promising findings prompted a clinical trial that is under way at Scripps Research Institute (NCT00974376).

Varenicline is a tobacco-cessation aid with demonstrated efficacy. It is a partial agonist at the $\alpha_{4} \beta_{2}$ subtype of the nicotinic acetylcholine receptor (nAChR) and a full agonist at the $\alpha_{7} \mathrm{nAChR}$, which has also been shown to bind with THC. In light of this binding similarity and the common concurrent use of cannabis with tobacco, varenicline was tested on five cannabis and tobacco users in a small case series. Four of the participants reported a reduction in the enjoyment obtained from cannabis and the amount they used. Nevertheless, all patients failed to complete the 12-week course of medication, due to a variety of reported side effects, such as headache, vomiting, and anger. Additionally, varenicline has been implicated in anger toward others. A larger study would be required to assess the utility of varenicline in the treatment of cannabis dependence, as well as close monitoring of adverse events. ${ }^{106}$

The most recent drug to be tested, vilazodone, a selective serotonin-receptor inhibitor and partial 5- $\mathrm{HT}_{1 \mathrm{~A}}$ agonist, was tested against placebo on a randomized group of 76 cannabisdependent adults. Participants received $40 \mathrm{mg}$ of vilazodone a day for 8 weeks, including brief motivational enhancementtherapy intervention and contingency management to encourage study retention. Vilazodone was found to provide no advantage over placebo in reducing cannabis use. ${ }^{110}$

\section{Conclusion}

Increasing cannabis prevalence results in an increase in harms associated with cannabis use, including cannabis-use disorder. With a growing number of users seeking treatment for cannabis-use disorders, there is a demand for targeted treatments and a wider range of evidence-based options. Comorbid substance-use disorders and mental health conditions are common, and should be assessed and treated concurrently. Although there is currently no evidence-based pharmacotherapy for the treatment of cannabis-use disorder, 
Table 1 provides a summation of the trials that have been conducted, and highlights the therapies that were least successful, such as the antagonist rimonabant. The most promising are the newer agonist therapies, such as nabiximols and nabilone, which have been found to reduce measures of withdrawal and relapse, warranting further exploration in the management of aspects of cannabis-use disorder.

It is anticipated that as the evidence base for full and partial $\mathrm{CB}_{1}$-receptor agonists is developed, these medications will become cost-effective and accessible. Pilot data and theoretical support for CBD make it an important cannabinoid to evaluate for the treatment of cannabis-use disorders with comorbid psychoactive and anxiety disorders. Different approaches yet to be explored include the inhibition of endocannabinoid catabolic enzymes, FAAH, and monoacylglycerol lipase, which reduces cannabinoid withdrawal in animal models with cannabinoid dependence. FAAH inhibitors appear to lack the abuse liability associated with cannabinoid agonists. ${ }^{10}$ A study examining the efficacy of FAAH inhibitors in reducing cannabis withdrawal in cannabis-dependent participants is under way at Yale University. The recent catastrophic preclinical trial of the FAAH inhibitor BIA 10-2474, however, sounds a new note of caution for future studies of compounds impacting the endogenous cannabinoid-receptor system for a range of indications.

\section{Disclosure}

Jan Copeland has received the medication Sativex and matched placebo from GW Pharma Pty Ltd only. The authors report no other conflicts of interest in this work.

\section{Refferences}

1. Hasin DS, Saha TD, Kerridge BT, et al. Prevalence of Marijuana Use Disorders in the United States Between 2001-2002 and 2012-2013. JAMA Psychiatry. 2015:1-9.

2. Ramesh D, Haney M. Treatment of Cannabis Use Disorders. Textbook of Addiction Treatment: International Perspectives. 2015:367-380.

3. Substance Abuse and. Mental Health Services Administration (2014) Results from the 2013 National Survey on Drug Use and Health: Summary of National Findings, NSDUH Series H-48, HHS Publication No.(SMA) 14-4863. Substance Abuse and Mental Health Services Administration, Rockville, MD. 2015.

4. Mehmedic Z, Chandra S, Slade D, et al. Potency Trends of $\Delta 9-T H C$ and Other Cannabinoids in Confiscated Cannabis Preparations from 1993 to 2008*. Journal of Forensic Sciences. 2010;55(5):1209-1217.

5. ElSohly M. Potency Monitoring Program quarterly report number 124. Reporting period: 12. 16/2013-03/15/2014.

6. Balter RE, Cooper ZD, Haney M. Novel pharmacologic approaches to treating cannabis use disorder. Current Addiction Reports. 2014;1(2):137-143.

7. Feingold D, Fox J, Rehm J, Lev-Ran S. Natural outcome of cannabis use disorder: a 3-year longitudinal follow-up. Addiction. 2015; 110: 1963-1974.
8. Haberstick BC, Young SE, Zeiger JS, Lessem JM, Hewitt JK, Hopfer CJ. Prevalence and correlates of alcohol and cannabis use disorders in the United States: results from the national longitudinal study of adolescent health. Drug and Alcohol Dependence. 2014;136:158-161.

9. Copeland J, Swift W. Cannabis use disorder: epidemiology and management. International Review of Psychiatry. 2009;21(2):96-103.

10. Canadian Centre on Substance Canadian Drug Summary: Cannabis. 2015:1-8. http:/www.ccsa.ca/Resource\%20Library/CCSA-CanadianDrug-Summary-Cannabis-2015-en.pdf. Accessed November 20, 2015.

11. Unted Nations Office on Drugs and Crime World Drug Report 2013. 2013. https://www.unodc.org/unodc/secured/wdr/wdr2013/World_ Drug_Report_2013.pdf. Accessed November 19, 2015.

12. Australian Institute of Health and Welfare National Drug Strategy Household Survey. Canberra 2011 Available from http://www.aihw. gov.au/WorkArea/DownloadAsset.aspx?id=10737421314. Accessed November 19, 2015.

13. European Monitoring Centre for Drugs and Drug Addiction. European Drug Report: trends and developments. Lisbon2013. Available from: http://www.west-info.eu/files/TDAT13001ENN1-11.pdf. Accessed November 19, 2015.

14. Johnston LD, Miech RA, O’Mallet PM, Bachman JG, Schukenberg JE. Use of alcoho, cigarettes and number of ilicit drugs declines among US teens. http:/www.monitoringthefuture.org/data/14data.html\#2014datadrugs. Published December 16, 2014. Accessed November 25, 2015.

15. Hooper SR, Woolley D, De Bellis MD. Intellectual, neurocognitive, and academic achievement in abstinent adolescents with cannabis use disorder. Psychopharmacology. 2014;231(8):1467-1477.

16. Kelly MA, Levin FR. Treatment of Cannabis Use Disorder.In: Galanter M, Kleber HD, Brady KT. Textbook of Substance Abuse Treatment. 5th ed. Arlington VA The American Psychiatric Publishing: 2014.

17. Beauvais F, Jumper-Thurman P, Helm H, Plested B, Burnside M. Surveillance of drug use among American Indian adolescents: Patterns over 25 years. Journal of Adolescent Health. 2004;34(6): 493-500.

18. Lee KK, Conigrave KM, Clough AR, Dobbins TA, Jaragba MJ, Patton GC. Five-year longitudinal study of cannabis users in three remote Aboriginal communities in Arnhem Land, Northern Territory, Australia. Drug and Alcohol Review. 2009;28(6):623-630.

19. Degenhardt L, Hall WD, Lynskey M, et al. Should burden of disease estimates include cannabis use as a risk factor for psychosis. PLoS Med. 2009;6(9):e1000133.

20. Degenhardt L, Whiteford HA, Ferrari AJ, et al. Global burden of disease attributable to illicit drug use and dependence: findings from the Global Burden of Disease Study 2010. The Lancet. 2013;382(9904):1564-1574.

21. Lorenzetti V, Solowij N, Fornito A, Ian Lubman D, Yucel M. The association between regular cannabis exposure and alterations of human brain morphology: an updated review of the literature. Current Pharmaceutical Design. 2014;20(13):2138-2167.

22. Solowij N. Cannabis and Cognitive Functioning. Cambridge University Press; 2006.

23. Meier MH, Caspi A, Ambler A, et al. Persistent cannabis users show neuropsychological decline from childhood to midlife. Proceedings of the National Academy of Sciences. 2012;109(40): E2657-E2664.

24. Grant BF. Comorbidity between DSM-IV drug use disorders and major depression: results of a national survey of adults. Journal of Substance Abuse. 1995;7(4):481-497.

25. Chen C-Y, Wagner FA, Anthony JC. Marijuana use and the risk of Major Depressive Episode. Social psychiatry and psychiatric epidemiology. 2002;37(5):199-206.

26. Rey JM, Tennant CC. Cannabis and mental health: More evidence establishes clear link between use of cannabis and psychiatric illness. British Medical Journal. 2002;325(7374):1183. 
27. Horwood LJ, Fergusson DM, Coffey C, et al. Cannabis and depression: an integrative data analysis of four Australasian cohorts. Drug and Alcohol Dependence. 2012;126(3):369-378.

28. Lev-Ran S, Roerecke M, Le Foll B, George T, McKenzie K, Rehm J. The association between cannabis use and depression: a systematic review and meta-analysis of longitudinal studies. Psychological Medicine. 2014;44(04):797-810.

29. Swift W, Hall W, Copeland J. One year follow-up of cannabis dependence among long-term users in Sydney, Australia. Drug and Alcohol Dependence. 2000;59(3):309-318.

30. Hingson R, Alpert JJ, Day N, et al. Effects of maternal drinking and marijuana use on fetal growth and development. Pediatrics. 1982;70(4):539-546.

31. Sherwood R, Keating J, Kavvadia V, Greenough A, Peters T. Substance misuse in early pregnancy and relationship to fetal outcome. European Journal of Pediatrics. 1999;158(6):488-492.

32. Klonoff-Cohen HS, Natarajan L, Chen RV. A prospective study of the effects of female and male marijuana use on in vitro fertilization (IVF) and gamete intrafallopian transfer (GIFT) outcomes. American Journal of Obstetrics and Gynecology. 2006;194(2):369-376.

33. Kadden RM, Litt MD, Kabela-Cormier E, Petry NM. Abstinence rates following behavioral treatments for marijuana dependence. Addictive Behaviors. 2007;32(6):1220-1236.

34. Taylor DR, Fergusson DM, Milne BJ, et al. A longitudinal study of the effects of tobacco and cannabis exposure on lung function in young adults. Addiction. 2002;97(8):1055-1061.

35. Fergusson DM, Horwood L, Swain-Campbell N. Cannabis dependence and psychotic symptoms in young people. Psychological Medicine. 2003;33(01):15-21.

36. Lynskey MT, Heath AC, Bucholz KK, et al. Escalation of drug use in early-onset cannabis users vs co-twin controls. JAMA. 2003;289(4): 427-433.

37. Degenhardt L, Hall W, Lynskey M. Exploring the association between cannabis use and depression. Addiction. 2003;98(11): 1493-1504.

38. Andrews G, Hall W, Teeson M, Henderson S. The Mental Health of Australians. Mental Health Branch, Commonwealth Department of Health and Aged Care Canberra; 1999.

39. Large M, Sharma S, Compton MT, Slade T, Nielssen O. Cannabis use and earlier onset of psychosis: a systematic meta-analysis. Archives of General Psychiatry. 2011;68(6):555-561.

40. Agrawal A, Lynskey MT, Bucholz KK, et al. DSM-5 cannabis use disorder: A phenotypic and genomic perspective. Drug and Alcohol Dependence. 2014;134:362-369.

41. Stinson FS, Ruan W, Pickering R, Grant BF. Cannabis use disorders in the USA: prevalence, correlates and co-morbidity. Psychological Medicine. 2006;36(10):1447-1460.

42. Anthony J. The epidemiology of cannabis dependence. Cannabis dependence: its nature, consequences and treatment, Cambridge University Press, Cambridge, UK. 2006:58-105.

43. Rosenberg MF, Anthony JC. Early clinical manifestations of cannabis dependence in a community sample. Drug and Alcohol Dependence. 2001;64(2):123-131.

44. Hasin DS, O'Brien CP, Auriacombe M, et al. DSM-5 criteria for substance use disorders: recommendations and rationale. American Journal of Psychiatry. 2013; 170:834-851.

45. Copeland J, Clement N, Swift W. Cannabis use, harms and the management of cannabis use disorder. Neuropsychiatry. 2014;4(1): 55-63.

46. Allsop DJ, Copeland J, Norberg MM, et al. Quantifying the clinical significance of cannabis withdrawal. PLoS One 2012;7:e44864.

47. Budney AJ, Moore BA, Vandrey RG, Hughes JR. The time course and significance of cannabis withdrawal. Journal of Abnormal Psychology. 2003;112(3):393.

48. Budney AJ, Hughes JR. The cannabis withdrawal syndrome. Current Opinion in Psychiatry. 2006;19(3):233-238.
49. Copeland J, Swift W, Rees V. Clinical profile of participants in a brief intervention program for cannabis use disorder. Journal of Substance Abuse Treatment. 2001;20(1):45-52.

50. Stephens RS, Roffman RA, Simpson EE. Adult marijuana users seeking treatment. Journal of Consulting and Clinical Psychology. 1993;61(6):1100.

51. Clapper JR, Mangieri RA, Piomelli D. The endocannabinoid system as a target for the treatment of cannabis dependence. Neuropharmacology. 2009;56:235-243.

52. Glass M, Brotchie J, Maneuf Y. Modulation of neurotransmission by cannabinoids in the basal ganglia. European Journal of Neuroscience. 1997;9(2):199-203.

53. Ashton JC, Glass M. The cannabinoid CB2 receptor as a target for inflammation-dependent neurodegeneration. Current Neuropharmacology. 2007;5(2):73.

54. Breivogel CS, Scates SM, Beletskaya IO, Lowery OB, Aceto MD, Martin BR. The effects of $\Delta$ 9-tetrahydrocannabinol physical dependence on brain cannabinoid receptors. European Journal of Pharmacology. 2003;459(2):139-150

55. Bobb AJ, Hill KP. Behavioral Interventions and Pharmacotherapies for Cannabis Use Disorder. Current Treatment Options in Psychiatry. 2014;1(2):163-174

56. Huestis MA, Gorelick DA, Heishman SJ, et al. Blockade of effects of smoked marijuana by the CB1-selective cannabinoid receptor antagonist SR141716. Archives of General Psychiatry. 2001;58(4):322-328.

57. Allsop DJ, Lintzeris N, Copeland J, Dunlop A, McGregor IS. Cannabinoid replacement therapy (CRT): Nabiximols (Sativex) as a novel treatment for cannabis withdrawal. Clinical Pharmacology and Therapeutics. 2015;97(6):571-574.

58. Huestis MA, Boyd SJ, Heishman SJ, et al. Single and multiple doses of rimonabant antagonize acute effects of smoked cannabis in male cannabis users. Psychopharmacology. 2007;194(4):505-515.

59. Benyamina A, Lecacheux M, Blecha L, Reynaud M, Lukasiewcz M. Pharmacotherapy and psychotherapy in cannabis withdrawal and dependence. Expert Reviews on Neurotherapeutics 2008; 8:479-491.

60. Levin FR, Kleber HD. Use of dronabinol for cannabis dependence: two case reports and review. American Journal on Addictions. 2008;17(2):161-164.

61. Haney M, Hart CL, Vosburg SK, et al. Marijuana withdrawal in humans: effects of oral THC or divalproex. Neuropsychopharmacology. 2004;29(1):158-170.

62. Haney M. The marijuana withdrawal syndrome: diagnosis and treatment. Current Psychiatry Reports. 2005;7(5):360-366.

63. Budney AJ, Vandrey RG, Hughes JR, Moore BA, Bahrenburg B. Oral delta-9-tetrahydrocannabinol suppresses cannabis withdrawal symptoms. Drug Alcohol Dependence 2007;86(1):22-29.

64. Levin FR, Mariani JJ, Brooks DJ, Pavlicova M, Cheng W, Nunes EV. Dronabinol for the treatment of cannabis dependence: a randomized, double-blind, placebo-controlled trial. Drug and Alcohol Dependence. 2011;116(1):142-150.

65. Bedi G, Cooper ZD, Haney M. Subjective, cognitive and cardiovascular dose-effect profile of nabilone and dronabinol in marijuana smokers. Addiction Biology. 2013;18(5):872-881.

66. Haney M, Cooper ZD, Bedi G, Vosburg SK, Comer SD, Foltin RW. Nabilone decreases marijuana withdrawal and a laboratory measure of marijuana relapse. Neuropsychopharmacology. 2013;38(8):1557-1565.

67. Blessing EM, Steenkamp MM, Manzanares J, Marmar CR. Cannabidiol as a Potential Treatment for Anxiety Disorders. Neurotherapeutics. 2015;12(4):825-836.

68. Pertwee R. The diverse $\mathrm{CB} 1$ and $\mathrm{CB} 2$ receptor pharmacology of three plant cannabinoids: $\Delta$ 9-tetrahydrocannabinol, cannabidiol and $\Delta$ 9-tetrahydrocannabivarin. British Journal of Pharmacology. 2008;153(2):199-215.

69. Mechoulam R, Peters M, Murillo-Rodriguez E, Hanuš LO. Cannabidiol-recent advances. Chemistry and Biodiversity. 2007;4(8): $1678-1692$ 
70. Machado Bergamaschi M, Helena Costa Queiroz R, Waldo Zuardi A, Crippa AS. Safety and side effects of cannabidiol, a Cannabis sativa constituent. Current Drug Safety. 2011;6(4):237-249.

71. Hayakawa K, Mishima K, Nozako M, et al. Repeated treatment with cannabidiol but not $\Delta 9$-tetrahydrocannabinol has a neuroprotective effect without the development of tolerance. Neuropharmacology. 2007;52(4):1079-1087.

72. Crippa J, Hallak J, Machado-de-Sousa J, et al. Cannabidiol for the treatment of cannabis withdrawal syndrome: a case report. Journal of Clinical Pharmacy and Therapeutics. 2013;38(2):162-164.

73. Morgan CJ, Freeman TP, Schafer GL, Curran HV. Cannabidiol attenuates the appetitive effects of $\Delta 9$-tetrahydrocannabinol in humans smoking their chosen cannabis. Neuropsychopharmacology. 2010;35(9):1879-1885.

74. Lichtman AH, Fisher J, Martin BR. Precipitated cannabinoid withdrawal is reversed by $\Delta 9$-tetrahydrocannabinol or clonidine. Pharmacology Biochemistry and Behavior. 2001;69(1):181-188.

75. Haney M, Hart CL, Vosburg SK, Comer SD, Reed SC, Foltin RW. Effects of THC and lofexidine in a human laboratory model of marijuana withdrawal and relapse. Psychopharmacology. 2008;197(1): $157-168$.

76. Haney M, Bisaga A, Foltin RW. Interaction between naltrexone and oral THC in heavy marijuana smokers. Psychopharmacology. 2003;166(1):77-85.

77. Haney M, Hart CL, Ward AS, Foltin RW. Nefazodone decreases anxiety during marijuana withdrawal in humans. Psychopharmacology. 2003;165(2):157-165.

78. Wachtel SR, de Wit H. Naltrexone does not block the subjective effects of oral $\Delta$ 9-tetrahydrocannabinol in humans. Drug and Alcohol Dependence. 2000;59(3):251-260.

79. Haney M. Opioid antagonism of cannabinoid effects: differences between marijuana smokers and nonmarijuana smokers. Neuropsychopharmacology. 2007;32(6):1391-1403.

80. Cooper ZD, Haney M. Opioid antagonism enhances marijuana's effects in heavy marijuana smokers. Psychopharmacology. 2010;211(2):141-148.

81. Greenwald MK, Stitzer ML. Antinociceptive, subjective and behavioral effects of smoked marijuana in humans. Drug and Alcohol Dependence. 2000;59(3):261-275.

82. Haney M, Hart CL, Vosburg SK, et al. Effects of baclofen and mirtazapine on a laboratory model of marijuana withdrawal and relapse. Psychopharmacology. 2010;211(2):233-244.

83. Haney M, Ward AS, Comer SD, Hart CL, Foltin RW, Fischman MW. Bupropion SR worsens mood during marijuana withdrawal in humans. Psychopharmacology. 2001;155(2):171-179.

84. Carpenter KM, McDowell D, Brooks DJ, Cheng WY, Levin FR. A preliminary trial: double-blind comparison of nefazodone, bupropion$\mathrm{SR}$, and placebo in the treatment of cannabis dependence. American Journal on Addictions. 2009;18(1):53-64.

85. Weinstein A, Gorelick DA. Pharmacological treatment of cannabis dependence. Current Pharmaceutical Design. 2011;17(14):1351.

86. Levin FR, Mariani J, Brooks DJ, et al. A randomized double-blind, placebo-controlled trial of venlafaxine-extended release for cooccurring cannabis dependence and depressive disorders. Addiction. 2013;108(6):1084-1094.

87. Cornelius JR, Clark DB, Bukstein OG, Birmaher B, Salloum IM, Brown SA. Acute phase and five-year follow-up study of fluoxetine in adolescents with major depression and a comorbid substance use disorder: a review. Addictive behaviors. 2005;30(9): 1824-1833.

88. Cornelius JR, Bukstein OG, Douaihy AB, et al. Double-blind fluoxetine trial in comorbid MDD-CUD youth and young adults. Drug and Alcohol Dependence. 2010;112(1):39-45.

89. McRae-Clark AL, Carter RE, Killeen TK, et al. A placebo-controlled trial of buspirone for the treatment of marijuana dependence. Drug and Alcohol Dependence. 2009;105(1):132-138.
90. McRae AL, Brady KT, Carter RE. Buspirone for treatment of marijuana dependence: a pilot study. American Journal on Addictions. 2006;15(5):404-404.

91. Levin FR, McDowell D, Evans SM, et al. Pharmacotherapy for marijuana dependence: a double-blind, placebo-controlled pilot study of divalproex sodium. American Journal on Addictions. 2004;13(1):21-32.

92. Bowen R, Mcllwrick J, Baetz M, Zhang X. Lithium and marijuana withdrawal. Canadian Journal of Psychiatry. 2005;50(4):240.

93. Winstock A, Lea T, Copeland J. Lithium carbonate in the management of cannabis withdrawal in humans: an open-label study. Journal of Psychopharmacology. 2008; 23:84-93.

94. Johnston J, Lintzeris N, Allsop DJ, et al. Lithium carbonate in the management of cannabis withdrawal: a randomized placebo-controlled trial in an inpatient setting. Psychopharmacology. 2014;231(24): 4623-4636.

95. McRae-Clark AL, Baker NL, Moran-Santa Maria M, Brady KT. Effect of oxytocin on craving and stress response in marijuana-dependent individuals: a pilot study. Psychopharmacology. 2013;228(4):623-631.

96. Potvin S, Stip E, Roy J-Y. The effect of quetiapine on cannabis use in 8 psychosis patients with drug dependency. Canadian Journal of Psychiatry. 2004;49(10):711.

97. Cooper ZD, Foltin RW, Hart CL, Vosburg SK, Comer SD, Haney M. A human laboratory study investigating the effects of quetiapine on marijuana withdrawal and relapse in daily marijuana smokers. Addiction Biology. 2013;18(6):993-1002.

98. Tirado CF, Goldman M, Lynch K, Kampman KM, Obrien CP. Atomoxetine for treatment of marijuana dependence: a report on the efficacy and high incidence of gastrointestinal adverse events in a pilot study. Drug and Alcohol Dependence. 2008;94(1):254-257.

99. McRae-Clark AL, Carter RE, Killeen TK, Carpenter MJ, White KG, Brady KT. A placebo-controlled trial of atomoxetine in marijuanadependent individuals with attention deficit hyperactivity disorder. The American Journal on Addictions. 2010;19(6):481-489.

100. Shafa R, Abdolmaleky HM. Inventors and assignees. Treatment of psychiatric disorders using entacapone, tolcapone and other COMT inhibitor or MB-COMT inhibitor drugs. United States patent US 20090012177 A1. 2009, Jan 8.

101. Gray KM, Watson NL, Carpenter MJ, LaRowe SD. N-acetylcysteine (NAC) in young marijuana users: an open-label pilot study. The American Journal on Addictions. 2010;19(2):187.

102. Gray KM, Carpenter MJ, Baker NL, et al. A double-blind randomized controlled trial of $\mathrm{N}$-acetylcysteine in cannabis-dependent adolescents. American Journal of Psychiatry. 2012;169(8):805-812.

103. Mason BJ, Crean R, Goodell V, et al. A proof-of-concept randomized controlled study of gabapentin: effects on cannabis use, withdrawal and executive function deficits in cannabis-dependent adults. Neuropsychopharmacology. 2012;37(7):1689-1698.

104. Mouzak A, Agathos P, Kerezoudi E, Mantas A, Vourdeli-Yiannakoura E. Transient Ischemic Attack in Heavy Cannabis Smokers-How 'Safe'Is It? European Neurology. 2000;44(1):42-44.

105. Mason BJ, Light JM, Williams LD, Drobes DJ. Proof-of-concept human laboratory study for protracted abstinence in alcohol dependence: effects of gabapentin. Addiction Biology. 2009;14(1):73-83.

106. Schifano F, D’Offizi S, Piccione $M$, et al. Is there a recreational misuse potential for pregabalin? Analysis of anecdotal online reports in comparison with related gabapentin and clonazepam data. Psychotherapy and Psychosomatics. 2011;80(2):118-122.

107. Schifano F. Misuse and abuse of pregabalin and gabapentin: cause for concern? CNS Drugs. 2014;28(6):491-496.

108. Smith BH, Higgins C, Baldacchino A, Kidd B, Bannister J. Substance misuse of gabapentin. British Journal of General Practice. 2012;62(601):406-407.

109. Newcombe DA, Walker N, Sheridan J, Galea S. The Effect of Varenicline Administration on Cannabis and Tobacco Use in Cannabis and Nicotine Dependent Individuals? A Case-Series. Journal of Addiction Research and Therapy. 2015; 6:2. 
110. McRae-Clark AL, Baker NL, Gray KM, Killeen T, Hartwell KJ, Simonian SJ. Vilazodone for cannabis dependence: A randomized, controlled pilot trial. The American Journal on Addictions. 2016;25(1):69-75.
111. Panlilio LV, Justinova Z, Goldberg SR. Inhibition of FAAH and activation of PPAR: new approaches to the treatment of cognitive dysfunction and drug addiction. Pharmacology and Therapeutics. 2013;138(1):84-102.

\section{Publish your work in this journal}

Substance Abuse and Rehabilitation is an international, peer-reviewed, open access journal publishing original research, case reports, editorials, reviews and commentaries on all areas of addiction and substance abuse and options for treatment and rehabilitation. The manuscript management system is completely online and includes a very quick and fair peer-review system. Visit http://www.dovepress.com/testimonials.php to read real quotes from published authors.

\footnotetext{
Submit your manuscript here: http://www.dovepress.com/substance abuse-and-rehabilitation-journal
} 